\title{
Evaluation of the changes of landscape types of Slovakia
}

\author{
Zita IZAKOVIČOVÁ ${ }^{1 *}$ \\ ${ }^{1}$ Institute of Landscape Ecology, Slovak Academy of Sciences \\ * Correspondence to: Zita Izakovičová, Slovak Academy of Sciences, Slovakia. E-mail: Zita.Izakovicova@savba.sk
}

\section{Article history}

Received: April 2013

Received in revised form:

July 2013

Accepted: August 2013

Available online:

September 2013
ABSTRACT: In the last period landscape protection, its representative types more and more comes to the limelight. In October 2000 the European Landscape Convention - also known as the Florence Convention was adopted. The aims of this Convention are to promote landscape protection, management and planning, and to organise European co-operation on landscape issues. Contracting states ought to analyse the landscape types on the whole area of their countries, to analyse their features, record their changes, specify motive power and pressure forming them and assess selected types with respect to special values attributed by engaged participants and inhabitants. Knowledge and identification of single landscape types enable the intensification of care of diversity of single landscape types and landscape biodiversity. It is an unavoidable condition in the strategic planning process and effective protection of regionally special landscape. Slovakia signed ELC in 2005 and became an active participant in its implementation. The Institute of the Landscape Ecology of Slovak Academy of Sciences elaborated methodology for specification and evaluation of the representative landscape types of Slovakia (RLTS). RLTS are defined as homogeneous units considering the landscape character, functions and current land-use. GIS (Geographical Information Systems) tool was used to create RLTS, in particular by overlaying of abiotic landscape structure (type of relief, quaternary deposits, climatic regions, and soil types) and land-cover map (CORINE Land Cover 2006 - CLC) at national scale. This process yielded to a patched map of homogeneous areas, which were further interpreted, generalized, and regionalized to a final map of RLTS. Landscape types of Slovakia were defined by the synthesis of the mentioned maps. Totally there were identified 126 basic landscape types. Each landscape type represents unique combination of land-use in different abiotic conditions and gives the unique environment for nature development In the second stage typing rare and unique landscape types of Slovakia have been marked. Following, all RLTS were evaluated from the point of view nature protection and recent degradation and threats. The main changes of RLTS were identified, taken into account also key driving forces of landscape changes and consequent pressures on the landscape. The final step included preparation of management proposal with aim to maintain all representative landscape types and to secure their sustainable development and protection. 


\section{Introduction}

During the recent period, representative types of landscape protection have increasingly come under the spotlight. It is not only scientists who now deal with landscape protection, but special attention is paid to this issue at a political level. In October 2000, the European Landscape Convention - also known as the "Florence Convention", was adopted. The aims of this Convention are to promote landscape protection, management and planning, and to organize European co-operation on landscape issues.

Each signatory is bound to undertake defined landscape quality objectives for identified and assessed landscapes. With the active participation of the interested parties and with a view to improving knowledge of its landscapes, they have undertaken:

$\square$ to recognize landscapes in law as an essential component of human surroundings, as an expression of the diversity of their shared cultural and natural heritage, and a foundation of their identity,

$\square$ to establish and implement landscape policies with a view to landscape protection, management and planning through adoption of specific set measures,

to establish procedures for the participation of the general public, local and regional authorities, and other parties,

- to integrate landscape into its regional and town planning policies and in its cultural, environmental, agricultural, social and economic policies, and also in other policies which can have possible direct or indirect impact on the landscape.

Contracting states must analyse the landscape types within their entire country, analyse their features, record their changes, specify motivating powers and pressures which form them and they must assess selected landscape types regarding special values attributed by both engaged participants and inhabitants. Acknowledgement and identification of the individual landscape types enable intensification of care for the diversity of single landscape types and landscape biodiversity. This is a mandatory condition for the strategic planning process and effective protection of regionally specialized landscapes.

Slovakia signed the ELC in 2005, and was an active participant in its implementation. The Institute of the Landscape Ecology of Slovak Academy of Sciences instituted methodology for specification and evaluation of the representative landscape types (RLTS) within Slovakia (Bezák, Izakovičová, Miklós et al. 2006).

The main goal of this paper is to specify the key drivers of landscape changes of Slovakia, and to evaluate its basic influences on the landscape character.

\section{Creation and characteristics of Representative Landscape Types in Slovakia (RLTS)}

RLTS are defined as homogeneous units considering the landscape character, functions and its current land-use. The Geographical Information Systems tool (GIS) was used to create RLTS, by 
overlaying the abiotic landscape structure, consisting of relief type, quaternary deposits, climatic regions, and soil types on the land-cover map (CORINE Land Cover 2006 - CLC) on a national scale. This process gave a patched map of homogeneous areas, which were further interpreted, generalized, and regionalized to form the final RLTS map (Bezák, Izakovičová, Miklós et al. 2006).

The geo-relief, as a main abiotic factor for landscape-ecological processes, was considered the most important abiotic factor for RLTS division (Miklós 2010). The three basic landscape categories of lowlands, basins and mountains were defined. Mountain landscape dominates Slovakia with approximately $53 \%$ of the total area, while the lowlands occupy $29 \%$ and basin landscape 18\%. The 5 lowland, 3 basins and 10 mountains sub-categories were specified, and these most closely describe forms of relief.

Land-use categories have been analysed according to CLC map since 2006. Eighteen basic units expressing different land use settings have been demarcated. The defined categories of land use were depicted in a scale of 1: 500,000. Agricultural landscape, with a prevalence of arable land, forms the dominant element of land use in Slovakia. Forests evaluated on the basis of prevailing species composition are also significantly represented. The third largest category is the combination of agricultural-forest landscape.

The Slovak Landscape types were defined by the synthesis of the above-mentioned maps. A total of 126 basic landscape types were identified wherein each landscape type represents a unique combination of land-use in different abiotic conditions, and provides the unique environment required for nature development.

Slovakia is dominated by a mountainous landscape with $53 \%$ of the area, while lowlands cover $29 \%$. The basin landscape, which covers $18 \%$ of Slovakia, has the smallest area. Basic landscape units, indicating natural landscapes types, are characterized as follows (Bezák, Izakovičová, Miklós et al., 2010):

a) Lowland landscape is among the oldest populated areas in Slovakia. This especially includes the areas of the Danube, Eastern and Borská Lowlands. These have the most productive soils, and agricultural production thus plays an important role there. This determines the visual character of the landscape, dominated by open land with a predominance of arable land and a small proportion of natural vegetation which is mainly concentrated along rivers and wetlands. Forests form a significant proportion of the Borská Lowland. Flood-plain forests previously dominated a substantial portion of the Danube Plain in the form of covered wetlands. However, these have largely been removed and turned into fields and meadows. Forest ecosystems have been preserved, mainly as bank vegetation, especially in the branch system of the Danube. Their existence is supported by the specific water regime of the Danube.

b) Basin landscape forms one of the most densely populated areas in Slovakia. This is also one of the oldest inhabited areas, especially in the low-lying basins. The basin landscape does not constitute a coherent area, but is fragmented into several areas, due to the configuration of the mountains. The nature of agricultural production in the lower basin is similar to the lowland landscape, and is dominated by the cultivation of cereals and vegetables, pig farming and also the development of food crop farming. Diverse agricultural production, with the prevalent cultivation of cereals, potatoes and significant farming of cattle for meat and milk, is significant in the more highly situated basins because of poorer climatic and soil conditions. Animal production (especially stockbreeding) and grassland methods of farming are quite prevalent in the highest-lying basins. The proportion of arable land is high in low- 
lying basins and reduced in higher-lying basins, where there is an increase in grassland, brush and forest areas. Visually, basins resemble an agricultural landscape which is slightly undulating with a more significant share of forest and shrubby vegetation, especially apparent towards the mountain ranges which form their border.

c) Mountain landscape comprises landscape with a rugged terrain, which allows partial agricultural use in the lower areas, with less intensive crop and livestock production. Forestry is also significant in this type of landscape. Rural settlements and small cities prevail in this landscape together with scattered settlements. More highly situated and broken areas are very sparsely populated, and settlements have a more recreational and spa function, as apparent in the High Tatras. Forestry prevailed in the past and remains prevalent today. Extensive animal production in both grasslands and in high mountain locations was most important in the past. Now, human economic activities are significantly limited by protection, because most mountain landscape regions are part of national parks or protected landscape areas. This landscape type is the most widespread in Slovakia.

Specific small-sized types of landscape and rare spatial structures can also be found in the territory of Slovakia. These represent an important landscape-ecological value and they are clearly distinguishable from the surrounding landscape. For this reason, the two categories of Unique and Rare Types were added. Their uniqueness and rarity are determined by:

- Uniqueness and rarity of the geological substrate and associated geo-morphological forms;

U Uniqueness and rarity of vegetation;

Uniqueness and rarity of spatial structure.

The Unique Types include landscape types of; the klippen belt, volcanic vents, and river arm systems as in the inner delta of the River Danube, plus the locality types identified by the UNESCO cultural and natural heritage. The Rare Types include landscape types of; karstic plateaus, high mountains, strato-volcanos and landscape types boasting historic landscape structures.

Special categories represent historical landscape structure. The following types of historical landscape structures have been identified in Slovakia: vineyard, meadow-pasture, dispersed settlement and mining landscapes. Of these historical structures, the largest area consists of landscape of dispersed settlement (6.3\%) and meadow-pasture landscape structure (4.8\%). The area covered by other historical landscape structures is less than $1 \%$ of the total territory of Slovakia.

\section{Specification of the key driving forces and character of the RLTS changes}

The current structure of the landscape in Slovakia is the result of long historical development. Changes in society which affected the landscape have been more rapid and more variable than the continuous natural processes of landscape development. These changes in society, whether technological, demographic, socio-economic or political, are reflected in the form of use, layout and appearance of the cultural landscape. Since each historical period and each stage of development imprints its specifics on the landscape, we can say that the cultural landscape is a true picture of the state and development of society. 
During historical development, humans have significantly influenced the structure of RLTS. This is mainly manifested by an expansion of human activities into original forest ecosystems resulting in their deforestation, and the subsequent transformation into agricultural land and especially arable soil. The basic drivers which influenced the Slovak landscape were:

- The period of industrialization and urbanization (after the $2^{\text {nd }}$ World War, the 1950s) - a period defined by a process of nationalization and industrialization of the countryside of Slovakia. A very sharp increase in industrial production gradually acquired a leading position in the structure of the economy. Approximately 300 new industrial plants were built and many increased production. Mass industrial production mainly concentrated on heavy industry, and was based on the unacceptable exploitation of natural resources and energy. Industrial pressures led to the increased consumption of wood. Open cast mining left large areas desolate, and the construction of industrial enterprises was aimed only at economic gains and at strengthening the economic standard of living. New employment was created, resulting in a gradual migration of the rural population to urban areas and consequent unsustainable concentration of the population in cities. On the other hand, this artificial migration process caused the abandonment of rural areas, with some rural settlements coming to life only on a seasonal basis. The above-limit concentration of the population in urban areas caused many negative effects, such as increasing demands for more residential space, which in turn caused significant anthropogenic pressures on the countryside. The emergence of uniform urban settlements ignored the town's specifics, failing to respect local cultural, historical and natural-geographical particularities of the environment. The soullessness of the 'super' blocks, significant suppression of human scale, gigantism, slowness, monotony, aesthetic and visual suppression of the principles of construction, flattening out and amorphousness of the living environment are the main features of the socialist urbanization of Slovakia. Industrial development and urbanization did not respect the environment. Many industrial operations harmed the environment to a disproportionate degree, thus producing excessive emissions that contaminated various environmental media. Natural resources were depleted and there was deterioration in the overall quality of the environment. Assessing the quality of the living environment was not given sufficient attention, therefore environmental quality was not regularly monitored and evaluated. In addition, information on the status of the environment was not disclosed and remained secret.

- The period of collectivization(1950's - 1960's) - a period defined by the expression of power and aggression, confiscation of property of small private farmers and the setting up of cooperatives. The cooperative movement in this period became the greatest enemy of the Slovak village. People were not prepared for such changes. Collectivization was primarily considered a political issue, not subject to social, cultural or psychological questions. The traditional forms of farming were destroyed along with the traditional rural life style (Slavkovský 2002). With this creation of cooperatives the process of collection and consolidation of land began, gradually leading to the formation of mono-functional agricultural landscapes. Hedges and terraced fields were ploughed up, grassland and meadows were destroyed. Some private owners voluntarily entered into a cooperative, some accepted it involuntarily, and the remainder changed and went to work in industry and services in neighbouring towns. In the years 1948 - 1950, 99,000 inhabitants left agriculture and went to work in industry. During this period, $80 \%$ of Slovak agriculture was collectivized. Agriculture then gradually lost its importance and declined over time, resulting in cooperatives of only older, mostly low-skilled workers. Agricultural production was focused 
mainly on the cultivation of cereals and fodder. In this period, cultivation in allotments was still relatively well preserved, behind houses and also on the outskirts of municipalities, thus creating a transition zone between urban and periurban. Allotment growing was used only for self-supply of family food. In wine-growing areas during this period, the allotments typically produced wine mainly for private consumption, but also partly for sale. However, in the mountainous areas, private farming managed to resist collectivization and some regions were able to preserve their typical traditional forms of farming, dominated by pasture meadows combined with small scale terraced fields. The remnants of these traditional farms form a valuable historical landscape structure in the countryside of Slovakia. A similar process of "nationalization" occurred in forestry, where forest land changed ownership, with a gradual increase in the area of forest owned by the state. Intensive logging began, with inappropriate forest management which threatened nature and the species composition of these forest ecosystems.

- Transformational changes (after 1989) - transformational changes after the revolution also affected the development of agriculture and forestry. Transition from central planning to a market economy brought with it many positives, but also a number of negatives. The loss of traditional markets, the under-developed land market and also input prices rising faster than returns from agriculture weakened the competitiveness of Slovak farmers in the marketplace. Even previously successful and well performing cooperatives began to crumble. First, livestock production was closed down since it was very labour intensive and unable to compete with products imported from neighbouring countries. Compared to 1990, pigs decreased by $70 \%$, cattle by $66 \%$ and sheep by $30 \%$ (Statistical Yearbook, 2006, Statistical Yearbook, 2010), and crop production also gradually decreased. The area of arable land in 2011 decreased by $6.2 \%$ compared to 1990 , from 1,509,000 ha to 1,416,633 ha. Finally, many agricultural cooperatives disintegrated and ceased operating. Only some dilapidated and abandoned buildings remain from the former united peasants' cooperatives and socialist intensive farming. Loss of these farms significantly weakened the economic base of many rural settlements, because agricultural cooperatives in many settlements had been the only source of income and employment. The transformational changes gradually began clarifying ownership. Possessions were returned to the original owners, but they were often no longer interested or they lacked the technical, financial or human resources to effectively farm the returned land. Less fertile land, and that with inadequate accessibility, is unmanaged and abandoned. These sites are the source and spread of synanthropic and invasive species. These socio-economic changes were also linked to changes in farming. The crop balance is diverse, with preference for crops commanding a lucrative price. Currently, in addition to cereals, mainly the energy crops including sunflower, corn and rapeseed are now grown. The area of energy crops has increased by $181 \%$, while the area of cereals has decreased slightly, by $5 \%$ (Statistical Yearbook 2006, Statistical Yearbook 2010). The largest falls were observed in forage, sugar beet and potatoes. Uncoordinated cultivation of energy crops can be a threat not only to natural ecosystems, but it can also threaten the individual landscape components. Significant decline in fruit growing and viticulture has been reported, where vines have decreased by almost half since 1990 , with the number of nuts reduced to $30 \%$ and the number of plums, pears and cherries decreased by half. Only apples have maintained steady numbers. Not only do vines and fruit suffer unfriendly socio-economic conditions, but climate change is also bringing the expansion of various diseases and the increased incidence of pests. From 1989 to 1994, 17 ha of orchards and vineyards were pulled up. Negative trends were also apparent in forest timber, where logging increased by $110 \%$ between 1991 
and 2009 (Statistical Yearbook, 2006, Statistical Yearbook, 2010). This overall management has gradually changed the balance of original trees, with proportion of spruce and pine significantly increasing while the proportion of indigenous trees such as fir and oak has significantly decreased.

In general:

- The lowlands and basin landscape types have been submitted to greatest changes, and here the most significant anthropogenic pressures on the natural ecosystems are clearly evident. Natural ecosystems such as forests and permanent grasslands were altered by urbanization, industrialization and the construction of artificial technological elements, industrial plants, servicing areas and communication systems. These types were also greatly affected by the development of agriculture, since these are the best quality areas with the most favourable climate for farming.

- The mountain and sub-mountain landscape types were modelled by the development of shepherding. The unrestrained development of grassland farming also practised above the upper timberline meant a distinct intervention into the natural ecosystems of alpine and subalpine areas. In addition to natural ecosystems, this also threatened soil and water resources. Water sources were endangered by animal excrement while the soil suffered from increased erosion.

- The most important negative changes in landscape structure, in aesthetic properties and overall characteristics of this landscape, took place during both industrialization and collectivization. The first mentioned phase affected settlement landscape within municipal boundaries, and the second influenced it outside the municipal boundaries. Industrial expansion was evident in creation of industrial mammoths accompanied by distinct anthropization of territory. Negative effects included the occupation of natural ecosystems and increased production of foreign substances which contaminated the environmental components. Agricultural collectivization also significantly intervened in the natural landscape. This triggered land consolidation and large-field management of the arable landscape and also elimination of the game refuges and eco-stabilizing vegetation. These all led to creation of a mono-functional agricultural landscape with a low level of ecological stability. The utilization of chemicals and mechanization also threatened the qualitative properties of both water and soil.

- The second important milestone in the change of landscape structure of RLTS was noted in structural changes in the Slovak Republic economy. The transition from the centrally planned economy to management based on market principles resulted in the disintegration and disappearance of many governmental bodies, including the ones managing agriculture. Many of the buildings and structures still stand abandoned and dilapidated, negatively affecting the image of the Slovak landscape. However, now industrial parks, commerce-servicing centres and recreational centres are often being established on green fields and in localities with rare natural resources. It occurs in protected areas and those with the best quality soil. A positive trend in conservation of the soil pool and protection of groundwater was noted following the reduced use of agricultural chemicals, although this was occasionally accompanied by the spread of weeds and invasive or synanthropic species. 


\section{Management of representative landscape types}

Preservation and protection of individual types of the Representative Landscape Types of Slovakia, especially the most unique and rare ones, requires the preservation of the important segments. Their optimal use and their protection must be ensured, and factors threatening the individual RLTS must be eliminated. To this end, it is necessary to apply and maintain the following measures:

a) Preservation of the current use of unique landscape types in Slovakia and protection of the klippen belt, volcanic vent and waterlogged depression landscape types. This includes the river arm system, types of landscapes in localities of the UNESCO world cultural and natural heritage, and also other unique types such as the RLTS of karstic plateaus, high mountains and strato-volcanos. Where legal protection of such types is non-existent it is necessary to declare them protected at a corresponding level of protection. This can be achieved under the framework of Protected Landscape Areas or Protected areas.

b) Preservation of the traditional forms of management in landscape types which contain historic landscape structures, such as wine-growing, meadow-pasture and dispersed forms of settlement. This preservation includes; establishment of economic and legal tools for their protection and support, a declaration of protected territories, support via subsidy policies, education and edification for encouragement of national and patriotic awareness.

c) Within individual RLTS: Strengthening of protection for the small-area Representative Ecosystems included among the priority biotopes of European significance.

d) Support for necessary spatial ecological stability within individual RLTS - building a functional territorial system of ecological stability with all Representative Ecosystems of the given region in the framework of biocentres. They should be added, completed or revitalized if necessary, and then subsequently protected.

e) Liquidation and degradation of alluvial woods and other linear elements should be averted. A direct cause of these phenomena arises from occupation for investment activities, or alternatively, these may be indirectly caused by an altered hydrological regime or through contamination.

f) Protection of historic landscape structures by applying suitable management for their protection and administration. Creation of an appropriate system of support for their management and preservation with grant schemes and legal protection, promotion, education and edification.

g) Settlement of indemnification and compensation of derogation to owners caused by the limited use of RLTS in their protection.

h) Protection and rational use of resources and potential within the framework of RLTS. This entails (1) not using the best quality land for investment projects, (2) applying means of soil plots management to ensure protection against physical and chemical degradation, (3) protecting water sources by appropriate use of hygienic zones which do not threaten water qualitative and quantitative properties and (4) the application of ecological forms of management in the forest ecosystems. 
i) Prevention of further contamination of RLTS components, and the implementation of technological measures concentrated on reducing negative impacts on the individual RLTS. This involves elimination of pollution sources in the individual environmental components, the revitalization and recultivation of damaged areas including the forest ecosystems, and the elimination of old environmental loads.

j) Building a comprehensive monitoring system aimed at the acquisition of information concerning changes, pressures, loads and threats to individual RLTS. This eventually aims to eliminate all negative trends in their development.

\section{Conclusions}

From a spatial viewpoint, mountain landscape types with a high rate of natural ecosystems are regions with the highest ecological quality, with a high ratio of original natural ecosystems (Meeus 1995, Washer 2005). In contrast, the least favourable ecological quality of spatial structures occurs in the lowland landscape types, such as in Podunajská rovina, Podunajská pahorkatina and Východoslovenská rovina. It also includes basins of Juhoslovenská kotlina, Dolnomoravský úval, and Považské podolie, where the large-area plough land or urbanized areas are the dominant elements in the landscape structure. The negative ecological quality of spatial structures is also typical in other basin regions, such as in Zvolenská, Turčianská, Žilinská, Žiarská and Pliešovská where the ratio of natural ecosystems does not exceed $30 \%$ of the total area.

From the viewpoint of RLTS, it is necessary to propose suitable management for individual RLTS and to identify an appropriate system for their management and protection. Within the intensively loaded and utilised landscape types, it is now necessary to carry out revitalization measures and to prevent their further degradation. Here, the most valuable natural and culturalhistorical landscape types must be protected and sensitively managed. Our main aim should be focused on improved protection for all those landscape types which currently have minimal or zero protection. These involve urban landscapes, and to a lesser extent, the protected vineyard landscapes and some agricultural-forest landscape types, such as the valuable mixed and coniferous landscape areas.

\section{Acknowledgements}

The paper is result of the solution APVV projects: APVV-0240-7 Model of representative geoecosystems on the regional level and APVV-0669-11 Atlas of landscape archetypes in Slovakia.

\section{References}

Bezák P., Izakovičová Z., Miklós L. et al. 2010. Representative types of Slovak Landscape. ILE SAS Bratislava, 180 pp.

Meeus JHA. 1995. Pan-European Landscapes. Landscape and Urban planning 31: 57-79. 
Miklós L, Izakovičová Z, et al. 2006. Atlas of the representative geo-ecosystems of the Slovak Republic. Institute of Landscape Ecology of Slovak Academy of Sciences, Ministry of Environment SR, Ministry of Education SR, Bratislava. $124 \mathrm{pp}$.

Miklós L. 2010. Landscape types of Slovakia. Map 1:500 000. Institute of Landscape Ecology, Slovak Academy of Sciences, Bratislava, Esprit Banská Štiavnica.

Slávkovský P. 2002: The agrarian culture of Slovakia - the transformation at the time. VEDA, Bratislava.

Statistical Yearbook of Slovakia. 2010. Statistical Office of the Slovakia, Bratislava: Veda, publishing SAS, $688 \mathrm{pp}$.

Statistical Yearbook of Slovakia. 1996. Statistical Office of the Slovakia, Bratislava: Veda, publishing SAS, $681 \mathrm{pp}$.

Washer DM (Ed). 2005. European Landscape Character areas. Typologies, Cartography and Indicators for the assessment of sustainable landscapes. ELCAI. Landscape Europe. Alterra. Wageningen. 